\title{
A Brief Analysis of Chopin Sonata OP35 No.2
}

\author{
Juan ZHANG \\ No.18 of dianzi road Yanta District Xi'an Shaanxi province , Music Department of Xi'an Shiyou \\ University \\ 494068277@qq.com
}

Key words: Chopin ,Sonata OP35 No.2, composing background ,music form , playing technique

\begin{abstract}
Chopin composed three Piano Sonatas in his lifetime, in which the most influential sonata is the second Sonatas. It is also one of the most popular works. This work expresses the author's strong patriotism. The four movements of music are not only independent but also related, every movement has their own character, but they can be organically combined. They express different emotions and artistic conception, but also foil each other, forming a strong contrast. The whole tune in a fierce and solemn emotional color ups and downs, which is Poland from prosperity to decline of the true portrayal of the history, but also express the author's patriotic feelings. This thesis will talk about Chopin's life background and introduces the sonata composing background, and analyzes the musical structure of music and playing skills on the track to give us a better understanding.
\end{abstract}

\section{Composer Introduction}

Chopin, Frederick Francois Chopin (F.F. Chopin), Polish, born in 1810.Both his composing and performance have remarkable accomplishments in his short life, he wrote about two hundred works, of which there are all kinds of different types, including Bolero, Barcarolle, lullaby, Fantasia Rondo, variations, and so on , his masterpiece: 2 Piano Concertos, 27 etudes, Scherzo, Ballade, impromptu each have four songs, and a piano trio, 3Piano Sonatas , Poirot his sixteen dances, seventeen songs, a total of twenty-one volumes.

Chopin has the title of "romantic piano poet", which can also reflect the important position of Chopin in the history of world music. He has a profound influence on the creation of later musicians. As one of the most important figures in the history of Poland music, Chopin is young demonstrated extraordinary talent, seven years old can play, the 12 year old entered the Warsaw international music schools of higher learning music and music theory, the development of Chopin's music talent buried foundation.

In Europe in the nineteenth Century, romantic music became the mainstream. The unique harmony and melodic grace of Chopin made Chopin have the title of "romantic piano poet".

Chopin is proficient in music creation and performance, focus on the piano, clear, his music theme of emotional, beautiful melody, simple, there are a variety of different subjects, combined with the life of the people of Poland, then Poland, Poland state historical conditions.

\section{Composing Background}

Second Sonatas, Op. "op 35", written in 1830s, at the time of the Chopin life in the Renaissance Center in France, although he has been in France for success, but at the time of the music performance pattern belongs to the social salon style, Chopin is difficult to have a good friend, miss her motherland far away from home a faithful friend is hard to find, troubled, Chopin has been depressed. Finally, in 1839, Chopin left the French capital Paris and lived in seclusion in the countryside of central France, where he met his love. The soothing environment influenced Chopin's mood and inspired Chopin's creative desire. The first theme of violent and peaceful second theme in stark contrast, but also a harmonious unity in the title of the idea.

This stage is a peak of Chopin's creation, through a period of gloomy time in Paris, let Chopin more mature, his works are more perfect. 


\section{Analysis of the Music Form}

This sonata has four movements, the first two movements are similar in style, and the latter two have a relatively big difference.

From the beginning of the piece, is the four deep sections, the tone of the tone leads to, the uneasy mood began to spread. In the main chord of B minor began to introduce the main part, start from here to rhythm faster, rhythm and speed in this in Allegro doubled, an expression of emotional anxiety, very excited, restless heart. Next, enter the minor after a slow pace, 2/2. See in this section, Chopin himself and the mood of the music to promote the logical, to enter the second stage of the theme, here, officially transferred to D flat minor. The whole chapter is solemn adagio, have many unique ideas, the part or the classical style of rhythm.

The author's enthusiasm is reflected in the following part of this part, in this part of reproduction, melody, music direction, beat, can see this point. The first movement structure is shown in figure 4-1:

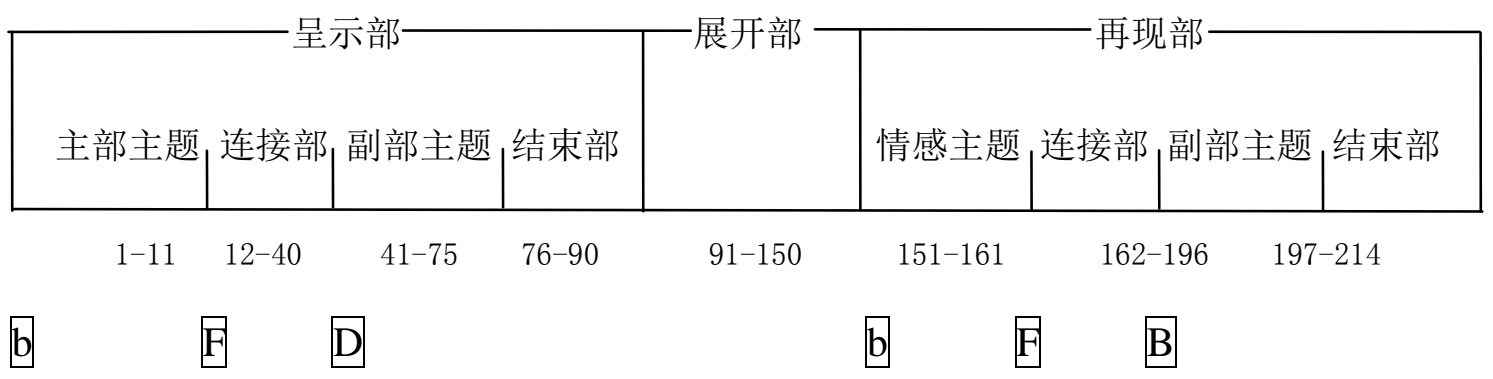

Figure 4-1

The second movement is a Scherzo, in particular, the song also lies in this, with six chord continuous half order tone, then gradually slowed down the speed of the music, and began to pop up, left hand chords sweet melody, make people feel at ease. Chopin mingled with a breath of horror, a clever fusion that made the whole effect even more shocking. In the last part, both hands continue to advance with the eight degree wave, and constantly strengthened. Because the third movement expressed indecisive feelings, so the whole movement of the tone is very slow, in accordance with the speed of Lento playing adagio. The first part of the composition in B minor tonality, while the second part of the middle section is D major tonality, the other is a reproduction of the single factor two form, the last part of the whole trilogy is a single type structure, is a kind of double Trilogy movement. This unique emotional tone is called funeral march.

The third movement structure is shown in figure 4-2:

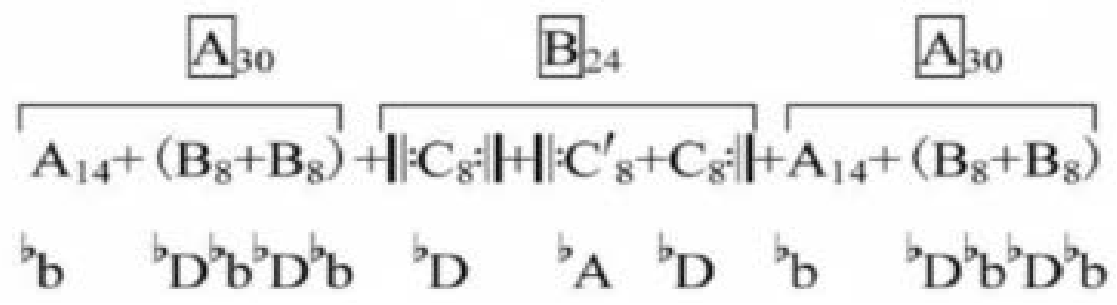

figure 4-2

The fourth movement is presto , the playing speed is very strict, very fast, but during the play no respite time, will give people a feeling of breath up, such a speed as no pause in the expression of a space and time is not the end the idea, in my opinion, Chopin is a kind of sad emotion expression, the time can not be back and the words can not express a kind of complex emotions.

Playing Technique The first movement is the grave, as shown in Figure 5-1 


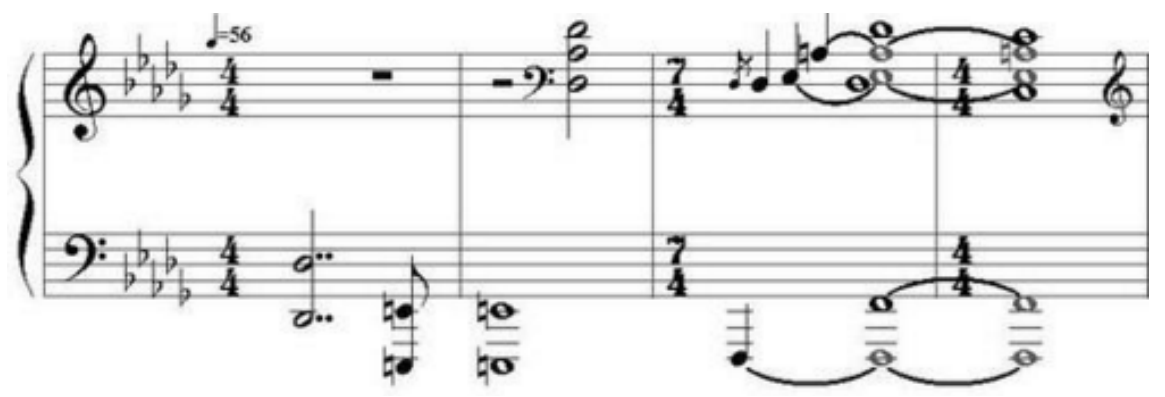

Figure 5-1

The opening is a heavy and passionate introduction, it indicates that the next part is very important, so we took this meaningful opening called the creative motivation, the third section, efforts will further strengthen the climax, there are more prominent rendering efforts. When playing, the decorative tone and the same note must be carried out simultaneously, which is the typical embodiment of Chopin's style. Thereafter, in sections 110th and $118^{\text {th }}$.

The composer used echo skills to express their emotion changes; in the one hundred and twenty and one hundred and twenty-one sections (Fig. 5-2 and 5-3 shows the creative motivation to) the movement the main motivation to express emotions have new sublimation, playing a good foundation for the 100th to the thirty-eight and one hundred and fifty-three sections of harmony the whole movement, emotional rendering to a new height.

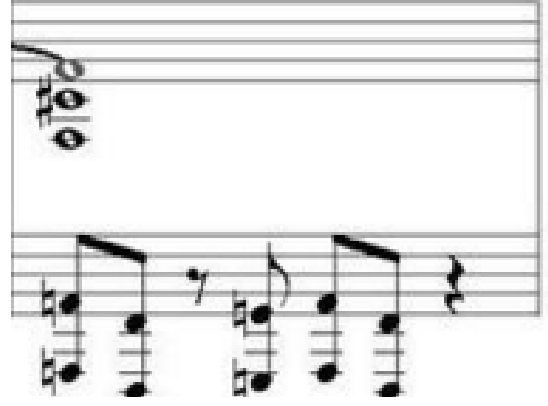

figure 5-2

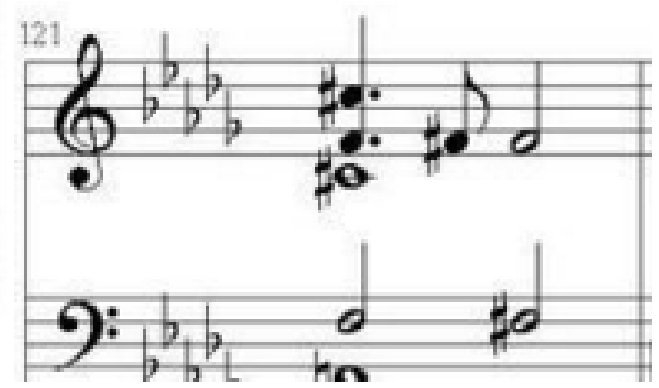

figure 5-3

The main part into the movement, we can take the first theme (agitato) structures were split, divided into four sections and two sections, by processing the phrase, which was short and incomplete, let the restless mood in each phrase are also very good, often to pedal in order to change, a clear distinction between legato and staccato, during the play, be very skilled carefully grasp the rhythm.

In accordance with the composer in opern of the mark, at the beginning of the fourth, twelfth, sixteenth sections for $\mathrm{F}$ performance, at the beginning of the thirteenth section by $\mathrm{P}$ play, when playing, you must learn to use the waist force, shoulders relaxed, slowly the waist force along the arm, the keys to the fingertips. Begin with the second part of the theme from the twenty-fifth section.

The composer, by adjusting the intensity of the more playing discordant harmony and collocation accented in some sections will be upbeat, sentiment further upgrade, Chopin's use in "Al Betty bass" left hand rhythm figure, and to adjust the Polish, also broaden the range. In the climax of the first theme, in the thirty-seventh, thirty-eighth section (Figure 4-5), 


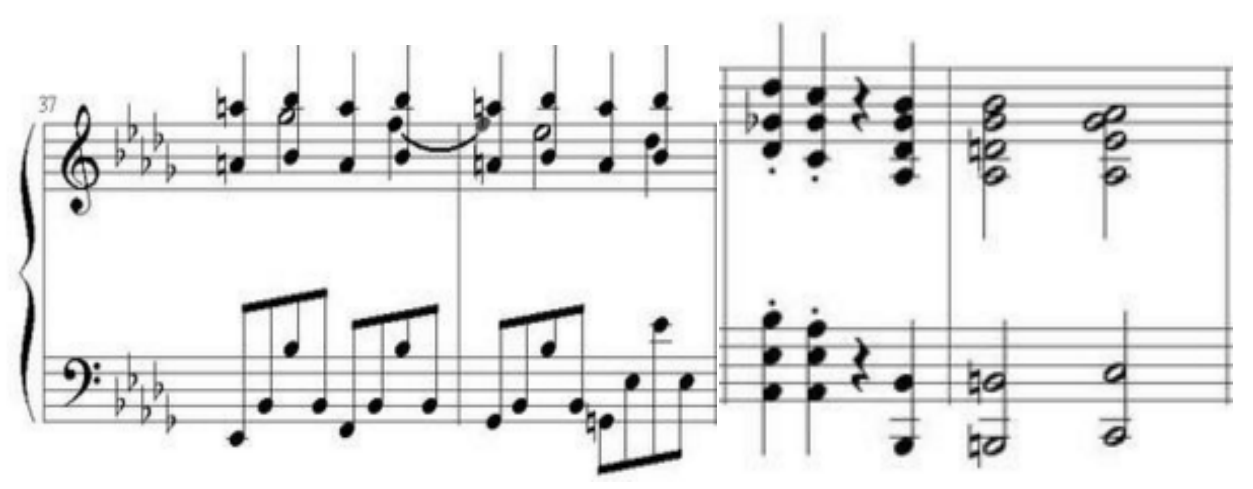

Figure 5-4

Figure 5-5

In the course of practice, to achieve fully skilled use of the left hand control playing rhythm, adjust to gentle properly, the strength of transformation can be matched with the natural transition and good performance at the right pace, let the whole performance showed similar expression of wheezing.

The second theme, in unexpected circumstances, has a slow, quiet pace, completely different from the high ups and downs of the past. Because of the movement in the process of playing fast and slow rhythm, transform very frequently, so in order to avoid the repeated changes make people feel confused phenomenon, to maintain smooth and clean in the pedal with clarity, so that every section of the theme expression, orderly.

The second movement begins with the two bar with the f mark, as shown in figure 5-6:

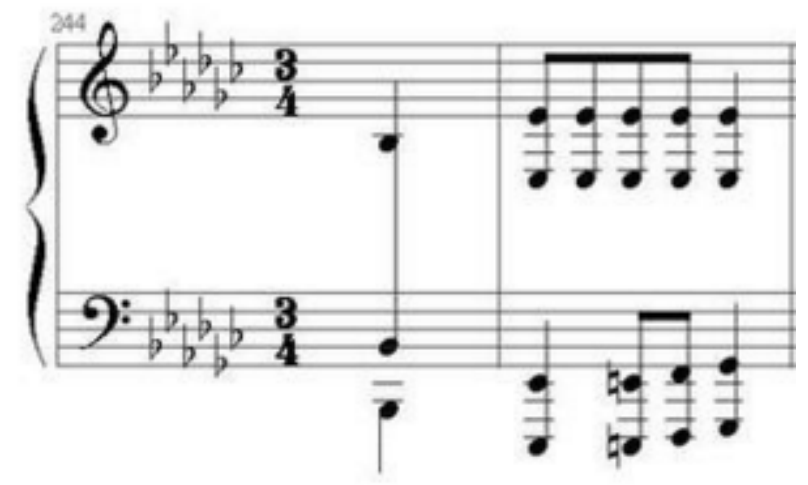

As a dominant motivation movement of the two sections, to a certain extent laid the entire play emotional tone, so play the two section is particularly important in the details to skip, leap and legato playing a strong clear distinction. From the thirty-seventh section , there will be half octave intervals, for this part to play in the process clear and orderly, with the body can be used on shoulders relax and sink, arm with a degree of relaxation state of play.

In the whole process of playing, we need to breathe calm, high concentration of spirit, tense at all times, when the entire repertoire of the end of the whole, and then adjust our tense mood and breathing.

\section{Conclusion}

Based on the brief analysis and study of Chopin Sonata Sonata OP35 No.2, makes us feel flexible but regular tonality layout, multi-dimensional musical elements, rich texture, bright color and language harmony change, and its high degree of difficulty performing skills and profound thought by the pianist and music theorists sought and respected.

\section{Reference}

[1] Qian Renkang. Brief history of European music [M]. Higher Education Press,2007

[2] Schuhmann. On the translation of music and musician [M]. Chen Dengyi. People's Education Press, 1960 
[3]Yu Zhigang. A brief history of western music [M]. Higher Education Press, 2013

[4]Yu Runyang. Tragic Chopin: Interpretation of the tragic connotation in Chopin's music [M]. Press of Shanghai Conservatory Of Music, 2008

[5]Liszt (Hungary). Lester of Chopin's [M]. Zhang Zemin et al. The People's music Press, 1978

[6]Wang Fengqi. Concise dictionary of music [M]. Shanghai Music Press, 2013 